\title{
Continuous Innovation: A Key to Retail Success
}

\author{
Prof. Rajni Y. Kshirsagar ${ }^{1}$ \\ ${ }^{1}$ (Department of Management Studies, Hirachand Nemchand College of Commerce, Solapur \\ Solapur University, Solapur Maharashtra, India)
}

\begin{abstract}
The Retail Sector is the largest sector in India after agriculture, accounting for over 10 per cent of the country's GDP and around 8 per cent of the employment. IT plays a crucial role in the retail industry. Retail is amongst the fastest growing sectors in the country and India ranks first, ahead of Russia, in terms of emerging markets potential in retail. Innovations in the retail industry are multi pronged and are aimed at enhancing the end user experience, optimizing resources and logistics, creating a technology platform to keep pace with the dynamics of the industry and manage the unprecedented growth given the geographic spread and diversity. Some of the key innovations include: Customer identification using RFID, E-Catalogue based selling, Mobile Point of Sale (POS), Digital Signage and Intelligent database. Innovations in Retailing India are still at an introductory phase, and in the process of understanding the benefits of IT in retail. It is indeed the beginning. The innovation and deployment that is taking place in India is confined to the organized sector. The way the Indian retail industry is shaping and developing presents an opportunity no less than a goldmine unearthed for vendors.
\end{abstract}

Keywords: Retailing, Innovations, Global Innovation Index.

1. To study scenario of retail industry in India.

2. To study innovative practices of organised retail.

\section{Introduction}

Indian retail sector is progressing tremendously with unbelievable innovations. It has played a phenomenal role throughout the world in increasing productivity of consumer goods and services. The Indian Retail Industry is the largest among all the industries, accounting for over 10 per cent of the country's GDP and around 8 per cent of the employment. The Retail Industry in India has come forth as one of the most dynamic and fast paced industries with several players entering the market. The India Retail Industry is gradually getting innovated and inching towards becoming the next boom industry. But the decline in the ranking of Third consecutive Global Innovation Index 2011 from 54 to 62 necessitates the support for the innovations in retailing in India. Provided with economical, social and political support for the innovators of the nation and rest of world they will definitely produce miracle in the field of Retail Management in India

Indian retail market is being observed as a potential market for investment. The quality expectations of the India's vast middle class and its almost untapped retail sector are key attractions for global investors in the retail market. This certainly indicates the necessity of innovations in the field of retailing in India. The flow of global funds will definitely bring innovations in the retail sector.

\section{Literature Review}

Kaushik Mukerjee in his article "Innovation Holds the Key" published in India Management September 2009 Explained that Innovation has long been the success mantra of many a company . But in a slowdown it seems to be the only tool to stay afloat and Successful innovation is the result of combination of ideas'

Report for NESTA December 2007 on "Innovation in the UK Retail Sector", recommended to i. Improve the effectiveness of innovation-related support activity within Government. ii. Increase the take-up of R\&D tax credits by the retail sector. Iii. Promote innovation in sustainability. iv. Identify and support the complex sets of skills required for retail innovation

R. Yuvarani in her article "PREVIEW OF RECENT TRENDS IN THE INDIAN RETAIL SECTOR" published in the online Sector View in July 2009, pointed out that The recent increased power of retailers has led to the introduction of new tactics by manufactures such as everyday low pricing, partnership with retailers and increased use of direct marketing methods.

Ram Prasad Sahu in his article "Retailers high on rising footfalls" published in Business Standard December 8, 2011 illustrated about the Improvement in operational performance, fresh equity investments and FDI proposals are well for the organised retail sector 
Neeraj Gandhi in his article "IT innovations in Indian retail" published in Express computers January 2008 Issue pointed that Indian retail is quite advanced in basic IT adoption like ERP, network, etc. compared to foreign retailers. However they have not managed implementation well due to lack of sector understanding both with clients as well as IT consultants.

Sreelatha Menon in her article" Unsung innovators ",published in Business Standard dated 16/11/ 2011 expressed that at least the innovators need is to be identified and aided by an angel investor. Neither are they identified nor is there any angel investor for them in India Manju Smita Dash In her article "Next-Generation Retailing In India: An Empirical Study Using Factor Analysis" published in International Review of Management and Marketing Vol. 1, No. 2, 2011, pp. 25-35 ISSN: 2146-4405 discussed about The Retail Industry in India has come forth as one of the most dynamic and fast paced industries with several players entering the market. But all of them have not yet tasted success because of the heavy initial investments that are required to break even with other companies and complete them.

\section{Mobile POS:}

\section{Innovations Undertaken By Organized Retailers}

This technology enables consumers to purchase goods while putting them in a shopping cart. The customer is spared the hassle of standing in long queues.

\section{Digital signage:}

Static signboards have not proved beneficial in terms of helping a customer track a product. Digital signboards integrated with an automated tracking system are expected to make this tracking easier.

\section{Intelligent database:}

Today, with technology advancements, a detailed database of customers can be made available online, to help the retailer understand a particular customer's buying characteristics and preferences. Indian and global IT service providers are working on a range of other retail innovations such as hi-tech store solutions, mobility solutions, shopping assistants, etc. that will ease daily operations and provide retailers the much needed competitive

\section{Cloud computing:}

For retailers seeking to gain greater results using minimal resources, cloud computing is like miracle. It allows retailers to invest less in maintaining, monitoring and updating shared working documents, email and operational data. It enables them instead to focus resources on store portals, social media, digital marketing, etc. Retailers have been quick to realize the benefits that cloud offers. Cloud computing enables retailer to efficiently manage the seasonal and unexpected demand as well weather-disastrous events. In a typical IT environment, retailers need to scale fixed data centre resources prior to demand spikes. This leads to wasted capacity and increased costs. Even worse, it can mean an under-supply, with network outages and crashed servers. However, by taking advantage of cloud computing, retailers can adjust to this dynamic demand. With cloud computing, retailers only have to pay for the level of service they need, without the costs of unused or under supply capacity. Lastly, cloud computing transforms how retail employees collaborate and share information. By implementing a hosted intranet with messaging, online meeting and social networking tools that span time zones and geographies, employees can collaborate more effectively, whether in the field, at headquarters or with a supplier. Cloud computing improves information flow and enables retailers to spend more time interacting with consumers.

\section{Innovative Marketing Strategies:}

Innovative Marketing strategy involves careful scanning of the internal and external environments. Internal environmental factors include the marketing mix, plus performance analysis and strategic constraints. External environmental factors include customer analysis, competitor analysis, target market analysis, as well as evaluation of any elements of the technological, economic, cultural, political and legal environment likely to impact success. A key component of innovative marketing strategy is often to keep marketing in line with a company's overarching mission statements. Once a thorough environmental scan is complete, a strategic plan can be constructed to identify business alternatives, establish challenging goals, determine the optimal marketing mix to attain these goals, and detail implementation. A final step in developing a marketing strategy is to create a plan to monitor progress and a set of contingencies if problems arise in the implementation of the plan.

\section{Customer Profiling:}

Customer profiling is, description of a customer group or type of customer based on various demographic, psychographic or geographic characteristics; also called shopper profile. For example, magazine advertising salespeople provide advertisers with customer profiles describing the type of person who will be 
exposed to advertisements in that magazine. The description may include income, occupation, level of education, age, gender, hobbies, or area of residence. Customer profiles provide the knowledge needed to select the best prospect lists and to enable advertisers to select the best media. Customer profiling is generally done to answer the basic marketing questions like:

- Who are the customers?

- What types of people are attracted to different offerings?

- What kinds of people live near to store location?

- What kinds of people live in a given geographic area?

- Where do certain kinds of people live?

Therefore, it is the customer description that includes demographic, geographic, and psychographic characteristics, buying pattern, creditworthiness, purchase history, etc. Customer profiling in Retail Sector, wherein invaluable information and data about customers and their transactions is observed and interpreted. The solutions are offered with the view to streamline marketing activities to increase the probability of returns. The analysis results in purchase acceleration, Brand switching, Basket effects and Store choice and maintenance of Price image. Owing to this comprehensive solution, clients have enjoyed benefits of easy customer acquisition, loyalty and sales growth.

\section{Merchandise Management:}

Clients can avail Merchandise Management solutions, which allows them implement retailing strategies. Experts are being appointed, who use apt techniques to study historical data, customer scorecards and their buying behavior. The retailers decide how to manage the merchandise depending on the customer profiling. The benefits of the solution are -

- Placement of items.

- Mount of stock to be displayed.

- Space for specific product/category.

- Placement of slow moving items in inventory.

- Planning for sales \& promotions.

- Display of new merchandise.

\section{Promotion design in Retail Store:}

With assistance of competent workforce, promotion solutions for esteemed clients are offered. The promotion is designed as per latest market trends after a thorough assessment of historical data and factors affecting retail sales. The promotional activities of the clients have helped them increase sales significantly. The promotion is designed as per latest market trends after a thorough assessment of historical data and factor affecting retail sales. Like Pantaloons uses its historical data based on customer profiling to design the promotional activities.

\section{Shop Floor Design Service:}

The comprehensive solution is offered after a detailed assessment and analysis of customer's buying behavior and premises. The designing strategy involves placement of stock at right place, display theme and other such factors. Market Placement Market placement here means, how the customers perceive as a brand. This includes various questions like,

- What percentage of customers are visiting store?

- How the customers perceive the other similar stores?

- How the customers perceive brand?

- What attracts them to Big Bazar?

- Are they satisfied with the ambience of the store?

All these and many more questions are being asked to the customers through the questionnaire from where the customers' perception about the store is taken. This helps the store manager to take proper action required to attract most customers in the given area where store is located and also to retain the existing customers. Thus market placement is an important criterion to be checked regularly by the retailers to improve the store performance.

\section{Competitor Profiling:}

The strategic rationale of competitor profiling is powerfully simple. Superior knowledge of rivals offers a legitimate source of competitive advantage. The raw material of competitive advantage consists of offering superior customer value in the firm's chosen market. The definitive characteristic of customer value is 
the adjective, superior. Customer value is defined relative to rival offerings making competitor knowledge an intrinsic component of corporate strategy. Profiling facilitates this strategic objective in three important ways. First, profiling can reveal strategic weaknesses in rivals that the firm may exploit. Second, the proactive stance of competitor profiling will allow the firm to anticipate the strategic response of their rivals to the firm's planned strategies, the strategies of other competing firms, and changes in the environment. Third, this proactive knowledge will give the firms strategic agility. Offensive strategy can be implemented more quickly in order to exploit opportunities and capitalize on strengths. Similarly, defensive strategy can be employed more deftly in order to counter the threat of rival firms from exploiting the firm's own weaknesses.

A common technique is to create detailed profiles on each of major competitors. These profiles give an in-depth description of the competitor's background, finances, products, markets, facilities, personnel, and strategies. This involves Marketing segments served, market shares, customer base, growth rate, and customer loyalty promotional mix, promotional budgets, advertising themes, ad agency used, sales force success rate, online promotional strategy distribution channels used, exclusivity agreements, alliances, and geographical coverage pricing, discounts, and allowances. A customer service in Retail Marketing is concerned with the exchange relationships that exist between a retailer and its customers. Quality and customer service are the key elements in this relationship. Today's competitive environment requires retailer to understand and apply properly the concept of relationship from the perspective of the customer and the other channel members. This will ensure that customers strongly believe that the retailer offers good value for money; and all the customer would like to do business with that retailer. The challenge of the retail unit is to bring three critical areas namely; marketing, customer service, and quality, into closer alignment. Relationship marketing attempts at bringing these areas together.

\section{Loyalty Programmes:}

Bases of loyalty programmes Retailers focus on loyalty programmes since it is believed that:

- Loyal customers are cheaper to serve.

- They are willing to pay more for a given bundle of goods.

They act as effective marketers for the store's offerings. Relationship rewards as part of loyalty programmes. Reward is a crucial part of any loyalty programmes. It has to be desirable enough to change the behavior of the customers. In fact, if the reward is really well chosen, it will be attractive to customers who are not really valuable to the business. There are various types of rewards like-Simple discount, a more targeted discounts, Points which lead to gift from a catalogue, Points which lead to later money offs, Extra services, etc.

\section{Tie-ups with Other Brands:}

Under loyalty programmes offering of membership cards to the customers have become a common trend today. Every retailer is providing some or other extra benefits to the customers through these cards. These cards not only the contain rewards but the particular retailer ties up with various other brands which provides some benefits to the loyal customers of the retailer.

For example, Pantaloons, one of the biggest brands in Indian retail have a Green Card for the loyal customers which provide benefits like-

- Per cent off in apparels every Friday.

- Fast and foremost information about sales and discounts.

- Free of cost alterations.

- Pick and drop facility after alterations.

- Facilities for jet airlines passenger through tie ups.

- Tie ups with Pizza hut, Aryans (restaurant), Pack and chew (restaurant).

\section{Promotions and Marketing:}

Promotional activities and events in a mall form an integral part of mall management. Activities like food festivals, handicraft exhibitions and celebrity visits increase foot traffic and in turn sales volumes. Organising cultural events has time and again proved vital in attracting consumers to a mall. Such activities may also act as a differentiator for a mall. Developers can work on drafting marketing strategies for individual malls to meet the needs of the local consumer base and the challenges of local, and in some cases, regional competitors. Big Bazaar is an example of a successful mall led by good promotions and marketing mall management practices. 


\section{RFID (Radio Frequency Identification) :}

Under this a shopping cart with a scanner and a touch screen computer offers information about each product and suggest complementarities. The computer keeps a list of items in the cart with a running total, so that we know exactly how much we are spending, When finished shopping we have to a self checkout stand or to a cashier. Since the items are already total and bagged, the wait time is minimal.

This involves identifying customers by issuing them smart cards embedded with smart chips. These cards would be RFID enabled and would give information regarding the customer like his preferences, shopping behavior etc.

\section{Conclusion}

That said, the innovation and deployment that is taking place in India is confined to the organized sector, which is a small proportion of the overall retail industry. The way the Indian retail industry is shaping and developing presents an opportunity no less than a goldmine unearthed for vendors. In addition, the unorganized sector-a sizable portion of the retail industry-is lagging behind in terms of IT usage. This is the reason why the IT percentage remains considerably low in the Indian retail industry. Even though technology is available to cater to this segment, factors like money, lack of education and comfort factor are playing spoilsport. "Even the unorganized sector is using IT, but it's largely user driven. The approach still remains traditional. In contrast; the organized sector seems to have reached a point of no return. The growth is constant and is expected to continue. It is here that a lot more innovation and development can be expected in the near future.

India's retail sector is witnessing a major transformation as traditional markets make way for modern and indigenously development retail formats. Standing on the threshold of a retail revolution and witnessing a fast changing retail landscape. Indian retail is still growing, and growing at an enviable rate. This growth supported with innovations will produce innovative results.

\section{References}

[1]. "IT innovations in Indian retail" by Neeraj Gandhi published in Express computers January 2008 Issue

[2]. "Innovations in the UK Retail Sector" Report for NESTA December 2007 Published by The Oxford I institute of Retail Management.

[3]. Empowering Retail Stores with Technical Ecosystems: is the Association with Information Technology Symbiotic by Anagha Shukre Published in the Review of Professional Management, Volume 6 Issue 1( Jan-June2008)

[4]. Unsung innovators "By Sreelatha Menon, published in Business Standard dated 16/11/2011

[5]. Next-Generation Retailing In India: An Empirical Study Using Factor Analysis" by Manju Smita Dash published in International Review of Management and Marketing Vol. 1, No. 2, 2011, pp. 25-35 ISSN: 2146-4405

[6]. Gibsn G. (2007) - Modern Retailing Comprehensive Policy Vital - The Hindu, p.p. 281-284.

[7]. Pugalanthi (2013) - Retail Market In India - International Journal of Social Science \& Interdisciplinary Research, Vol. 2 (7), JULY (2013) 